\title{
MAIN TENDENCIES IN DEVELOPMENT OF PLASMA-ARC WELDING OF ALUMINIUM ALLOYS*
}

\author{
A.A. GRINYUK ${ }^{2,3}$, V.N. KORZHIK ${ }^{1,2}$, V.E. SHEVCHENKO ${ }^{1,2}$, A.A. BABICH ${ }^{2}$, \\ S.I. PELESHENKO ${ }^{4}$, V.G. CHAJKA ${ }^{2}$, A.F. TISHCHENKO ${ }^{2}$ and G.V. KOVBASENKO ${ }^{2}$ \\ ${ }^{1}$ Chinese-Ukrainian E.O. Paton Welding Institute \\ (Guangdong General Research Institute of Industrial Technology) \\ (Guangzhou Research Institute of Non-Ferrous Metals, PRC) \\ ${ }^{2}$ E.O. Paton Electric Welding Institute, NASU \\ 11 Bozhenko Str., 03680, Kiev, Ukraine. E-mail: office@paton.kiev.ua \\ ${ }^{3}$ NTUU «Kiev Polytechnic Institute» \\ 6/2 Dashavskaya Str., 03056, Kiev, Ukraine. E-mail: andrey_grinyuk@ukr.net \\ ${ }^{4}$ South China University of Technology \\ 510641, Guangzhou, PRC. E-mail: sviatoslav@qq.com
}

\begin{abstract}
Publications, describing the characteristic technologies of aluminium alloy welding by an arc constricted by high-velocity inert gas flow were analyzed. It is shown that plasma-arc welding (PAW) is further development of the process of nonconsumable-electrode inert-gas welding. It is established that during development of PAW of aluminium alloys, there was a transition from alternating sinusoidal current to reverse polarity direct current, and furtheron to variable polarity asymmetrical current with rectangular current waveform. A more promising direction of improvement of PAW equipment is transition from specialized power sources to modular design of PAW system, based on power sources applied for nonconsumable electrode welding and plasma modules. Further path of improvement of the processes of aluminium alloy PAW is combined or hybrid application of several heat sources, including the constricted arc and consumable-electrode arc. In the authors' opinion, hybrid consumable-electrode PAW with hollow anode and axial wire feed in the most promising variant. 41 Ref., 17 Figures.
\end{abstract}

Key words: plasma-arc welding, aluminium alloys, alternating sinusoidal current, variable polarity asymmetrical current, hybrid plasma-arc welding, consumable electrode

Aluminium and aluminium alloys take up the second place after steel as to production and consumption. Owing to a set of physical and mechanical, corrosion and technological properties, aluminium-based light alloys are successfully applied not only in development of flying vehicles, but also in other sectors of industry and construction. Volumes of aluminium alloy application in military equipment items, in shipbuilding, in fabrication of automotive and railway vehicles, in electrical engineering, in manufacture of cryogenic and chemical apparatuses, in agricultural and food industry are considerable. Alongside a multitude of diverse welding processes, arc welding processes are more widely applied to produce aluminium alloy permanent joints, which can be divided into nonconsumable and consumable electrode welding. Nonconsumable electrode welding is applied in fabrication of structures from semi-finished products of aluminium alloys 2-12 mm thick. In its turn, nonconsumable electrode welding is performed by freely expanding and constricted arc.

The first mention of plasma jet energy application for metal treatment dates back to 1950 s [1]. Nowadays the plasma jet is used for welding, cutting, coating deposition, surface hardening, etc. Transferred and non-transferred constricted arc is applied for metal treatment. At transferred arc application the electric discharge runs between the electrode and the item, and in the case of non-transferred arc the discharge runs between the electrode and the plasma nozzle. In this case, the treated item is exposed only to a plasma jet blown out through small diameter nozzle by inert gas flow.

Fusion welding with heating by constricted plasma arc is a further development of inert-gas nonconsumable-electrode welding process [2]. Another inner water-cooled copper nozzle is

\footnotetext{
* Work was performed with financial support within Program of Foreign Experts in PRC \#WQ20124400119, R\&D Project of Innovation Group of Guangdong Province \#201101C0104901263 and International Project of Ministry of Science and Technology of PRC \# 2013DFR70160.
} 

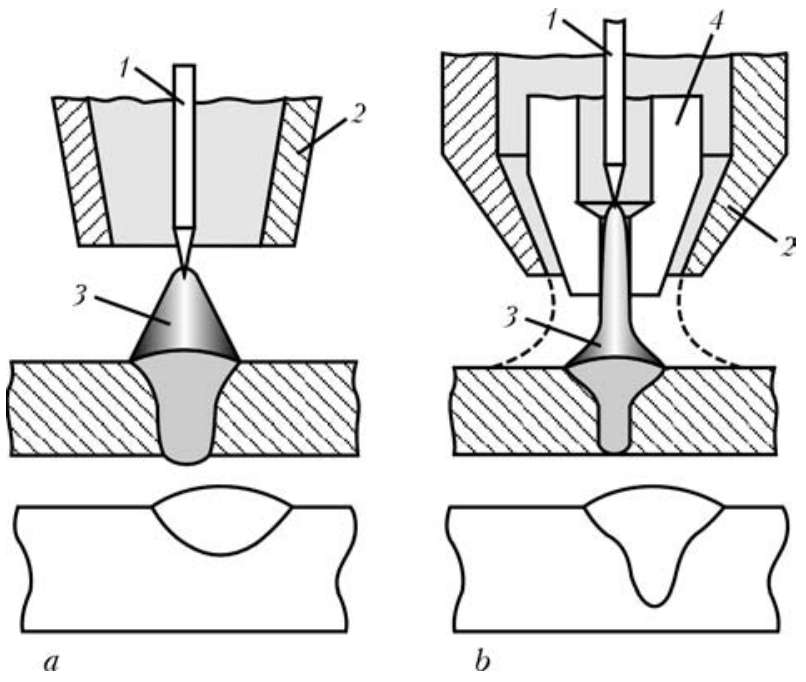

Figure 1. Schematic of the process and shape of weld penetration in nonconsumable electrode arc $(a)$ and plasma-arc (b) welding: 1 - tungsten electrode, 2 - shielding gas nozzle; 3 - welding arc; 4 - plasma-forming nozzle

added to the torch design. Gas, blown out through inner nozzle hole of small diameter (from 1 to $5 \mathrm{~mm}$ ) forms a layer of thermal and electric insulation around the arc, preventing its free expansion. Welding zone is protected by inert gas flow from larger diameter outer nozzle ( $F i-$ gure 1), and arc column temperature and its voltage rise [2].

On the whole, analysis of the experience of plasma arc application for welding showed that it is a more versatile source of metal heating in welding, compared with electric arc in nonconsumable and consumable electrode welding. Compared to these methods, plasma provides deeper penetration of metal at simultaneous reduction of its melting volume, and it also has the following advantages:

- higher plasma arc temperature (up to 18,000-25,000 K);

- smaller arc diameter;

- arc cylindrical shape (unlike the regular conical shape);

- plasma arc pressure on the metal 6-10 times higher than that of a regular one;

- ability to maintain the arc at low currents $(0.2-30 \mathrm{~A})$.

Plasma arc application in welding also ensures absence of metal spattering, smaller heating of base metal and, consequently, its smaller deformation, no need for edge preparation (grooving) in many cases due to high penetrability of the plasma arc, higher cost effectiveness and efficiency (by 2-3 times and more), reduction of the cost of machining at butt preparation for welding, and of weld treatment after welding by $3-5$ times and more, lower consumption of welding consumables by 3 to 5 times or more, weld quality improvement and possibility of $100 \%$ automation of the processes of welding the longitudinal and circumferential welds.

According to GOST 2601-84 «Metal welding. Terms and main definitions», fusion welding with heating by an arc constricted by gas flow, is called plasma welding. In our opinion, such a definition is more suitable to the process of welding by nontransferred constricted arc, which is usually not used for welding. Therefore, it is more correct to apply the term «plasma-arc welding», which specifies participation of both the arc energy, and plasma jet energy, in part heating.

Plasma-arc welding with alternating sinusoidal current. A feature of aluminium alloy arc welding is the need to break up the surface refractory oxide film. For its effective breaking up, plasma-arc welding (PAW) should be performed at reverse polarity direct current or at variable polarity current [3].

Similar to the case of nonconsumable electrode welding with freely expanding arc, the first experiments on PAW of aluminium alloys were conducted with application of alternating sinusoidal current of $50 \mathrm{~Hz}$ frequency. At the end of 1960s, PWI performed intensive studies of this process [4, 5]. To ensure constricted arc running, a pilot arc module was added to a standard machine for nonconsumable electrode aluminium welding. The pilot arc ran between the electrode and plasma-forming nozzle, ionizing the gap between the electrode and the item. At application of sinusoidal AC, oxide film breaking up proceeds in reverse polarity half-wave at electrode positive. Up to $70 \%$ of the arc heat evolves in the electrode. In 1970-1971 the method of PAW with sinusoidal AC was applied in ship-building. An advanced automatic machine «Aluminij-1» for nonconsumable electrode welding of aluminium alloys and UDG-701 power source were proposed for its realization [6]. This welding process did not become widely accepted later on. There is no information in publications about batch-produced machines for PAW at sinusoidal AC.

Plasma-arc welding at reverse polarity direct current. PAW at reverse polarity was applied for the first time for joining $6.35 \mathrm{~mm}$ aluminium alloy sheets by the staff of Thermal Dynamics Corporation [7]. The first studies in the Soviet Union on application of DCRP date back to the beginning of 1970s [8, 9].

The best cathode breaking up of the film (cathode cleaning) in nonconsumable electrode welding is achieved at reverse polarity. Plasmatron electrode assembly is the anode, and the item proper is the cathode. PAW at DCRP is easier to implement, compared to sinusoidal AC welding. For instance, standard welding rectifiers can 
be used as the constricted arc power source. Nonetheless, this PAW process has a significant drawback - a considerable amount of heat evolves in the electrode assembly at reverse polarity welding, leading to electrode premature failure.

In order to extend the service life of electrode assembly, its intensive cooling is performed, tungsten rods of large diameter $\left(8^{-10} \mathrm{~mm}\right)$ or special copper electrodes with inserts of refractory materials (tungsten, hafnium) are used. To extend plasmatron life, its components are made massive, that increases its overall dimensions.

Stability of running of a constricted direct current arc at reverse polarity depends on the quality of part surface preparation for welding. Presence of unremoved oxide films on the surface of items being welded can cause wandering of the heating spot, because of different emissivity of the oxide film and cleaned base metal $[8,9]$. At small currents this wandering will become more pronounced.

The process was widely applied for manufacturing items from aluminium alloys for cryogenic applications [10]. UPS-301 and UPS-503 machines were manufactured in the USSR for PAW at DCRP, and welding could be also performed with surfacing machine UPNS-304.

Studies of this variant of PAW of aluminium are intensively pursued in Russia. Company «Shipbuilding and Ship Repair Center» developed PPN-200 semi-automatic machine for PAW of aluminium at DCRP. Nonconsumable electrode welding machine Master-2500 of Kemppi is used as the power source [11]. Company «Plazmek» Group developed a versatile PAW station, including an inverter power source, module for pilot arc generation and plasma gas feeding, independent water-cooling unit and proprietary plasmatrons. List of companies, manufacturing equipment for direct current PAW is extensive: it can include companies from North and South America, Europe and Asia. The following equipment models can be noted: DigiPLUS A7P and DigiPLUS A7PO of IMC Engenharia de Soldagem (Brazil), Ultima150 of Thermal Arc (USA), PI400 Plasma of Svejsemaskinefabrikken Migatronic A /S (Denmark), Plasmaweld 402 of L-TEC Schweisstechnik (Germany), PSI 350plus of Kjellberg Finsterwalde Schweisstechnik und Verschleissschutzsysteme (Germany), Tetrix 552 RC Plasma CW of EWM Hightec Welding Automation (Germany), PW400 of Arcraft Plasma Equipment PVT. Ltd (India), Plasma 500XP of Powwel Co. Ltd (Korea), and others.

To increase the effectiveness of PAW at DCRP, Russian scientists proposed pulsed feed of plasma gases [12-14].

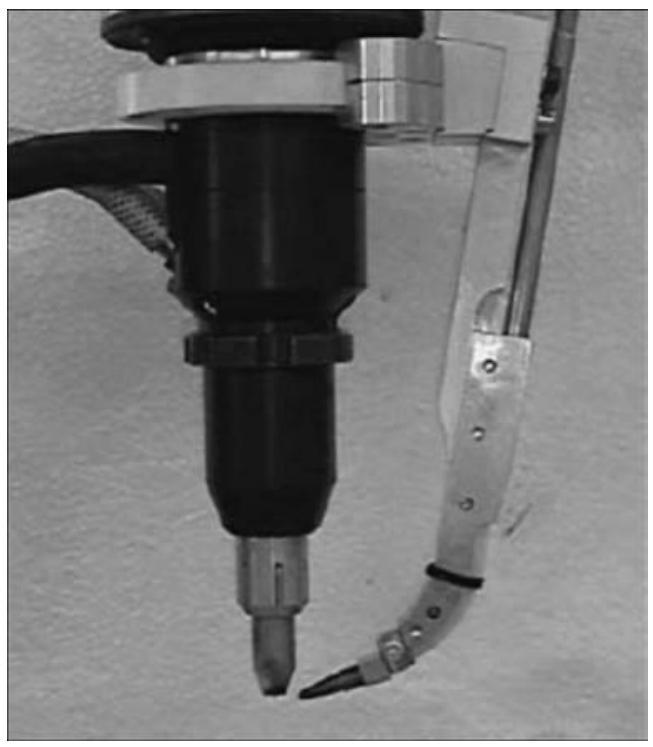

Figure 2. Appearance of Plasmatron welding torch (Inocon Technologie GmbH) [16]

One of the negative points of DCRP application for PAW of aluminium alloys is a strong proneness of this welding process to hydrogen gas porosity in the weld metal [15].

Plasmatron welding process proposed by Inocon Technologie GmbH (Austria) is one of the variants of PAW of aluminium alloys at direct current [16]. An ingenious shape of the welding torch is a feature of the welding process (Figure 2). As reported by Inocon Technologie GmbH staff, such a scheme of the welding process allows temperature in the active heating spot to be increased (Figure 3), and welding to be performed without an additional module of pilot arc generation.

Plasma-arc welding of aluminium alloys with alternation of electrode and plasma-forming nozzle polarities. To reduce the adverse impact of heat evolved in the electrode at current passage during reverse polarity half-wave, and preserve sufficient cathode cleaning of the weld, PWI staff proposed an original method for applying voltage to the plasmatron [17]. During straight polarity half-wave the arc ran between the tungsten electrode and the item, and during the reverse polarity half-wave the arc was excited between the item and copper plasma-forming nozzle. Owing to such a schematic of energy application to the plasmatron, good penetration was achieved, tungsten electrode resistance was improved, and the arc running during reverse polarity halfwave, ensured effective breaking up of the oxide films. However, this equipment for PAW of aluminium alloys was not put into batch production. At present, German scientists revisited the idea of separate feeding of energy to the electrode and the plasma-forming nozzle. Their machine for 

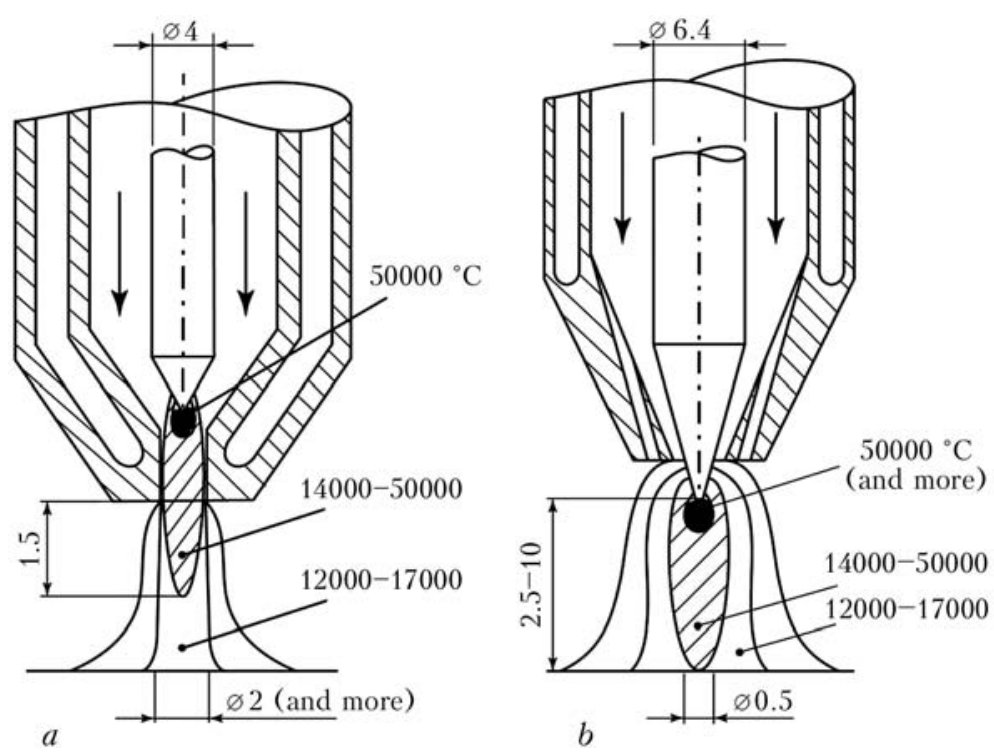

Figure 3. Temperature distribution in traditional torch for PAW $(a)$ and Plasmatron welding torch of Inocon Technologie $\mathrm{GmbH}(b)$ [16]: $a-$ heat flow surface density of $10^{3}-10^{5} ; b-10^{6} \mathrm{~W} / \mathrm{cm}^{2}$

PAW with alternation of the electrode and the plasma-forming nozzle polarity also is still at the laboratory stage.

Plasma-arc welding by variable polarity asymmetrical current with rectangular waveform. Process of PAW by variable polarity asymmetrical current with rectangular current waveform, called Variable Polarity Plasma Arc (VPPA) welding, was registered by Hobart Brothers Inc. in 1978 [18]. A special module, forming an additional pulse at transition from straight to reverse polarity, was incorporated into the design of welding machines generating sinusoidal welding current, to ensure continuous arcing. Rectangular waveform of welding current allowed ensuring reliable arc excitation at polarity reversal without application of a special module. To lower the thermal impact on the torch electrode assembly, PAW by variable polarity current with rectangular waveform was performed with prevalent flowing of straight polarity current. Minimum admissible duration of current flowing at reverse polarity is selected to ensure effective cathode breaking up of the oxide films. The ratio of duration of current flowing at straight and reverse polarity was equal to approximately 3:1. Current amplitude at reverse polarity was approximately by 30-40 A higher than at straight polarity (Figure 4) [19]. Reduction of the amount of heat evolving in electrode

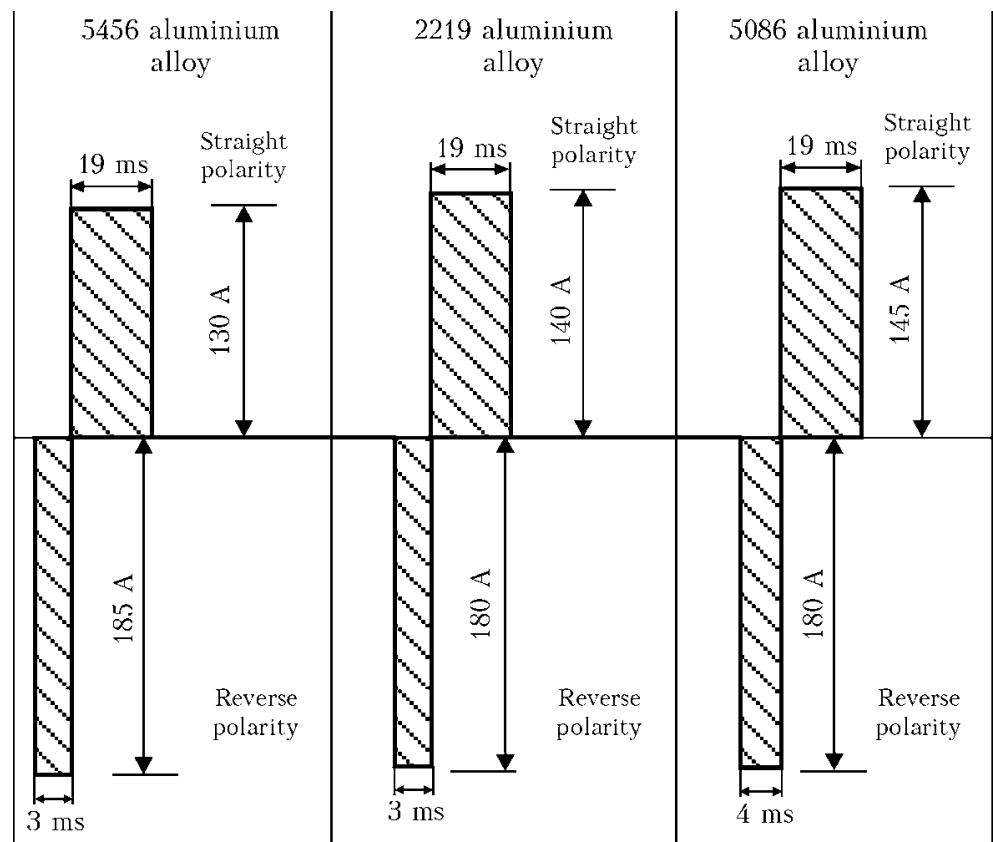

Figure 4. Amplitude and duration of current flowing at straight and reverse polarity for VPPA welding aluminium alloys of different composition [18] 
assembly allowed increasing plasmatron performance and reducing its geometrical dimensions.

In 1972, Sciaky proposed to Boeing to use variable polarity asymmetrical current with rectangular waveform for PAW of aluminium alloys [20]. Sciaky power source, however, did not provide arcing stability at variable polarity asymmetrical current. In 1974, Hobard Brothers Inc. started development of a power source and set of equipment for PAW at variable polarity asymmetrical current of rectangular waveform for Boeing. In 1979, the first such set of equipment for PAW was supplied to Marshall Space Flight Center. The set was based on VP-300-S power source, actual values of welding current were monitored with Cyber-Tig 11 Series 800 Programmer. This set of equipment and its subsequent analogs were widely used for fabrication of fuel tanks for liquid hydrogen and oxygen of Space Shuttle system [21-23]. In 1990s, Hobart Brothers Inc. stopped manufacturing equipment for VPPA welding process. At the same time, the demand of US space industry in the field of PAW of aluminium alloys by variable polarity asymmetrical current is satisfied by products of $\mathrm{Li}^{-}$ burdi, Canada (LTP400-VP power source) ( $\mathrm{Fi}$ gure 5) and AMET, USA (VPC450 power source). High cost of equipment and complexity of operation did not promote wide acceptance of this welding process by industry.

VPPA welding at asymmetrical current was the most effectively applied for gravity welding of joints without using backing elements with forming grooves. Such a process was called «keyhole» (Figure 6). In this process the plasma jet penetrates right through the weld pool molten metal, forming a through-thickness channel, which exists during the entire period of welding. Through-thickness penetration of the plasma jet completely eliminates oxide film inclusions in the weld, and also reduces item deformation, due to homogenizing of heating of the parts being welded by height. $100 \%$ argon was used as plasma gas, and $100 \%$ helium was the shielding gas.

More active application of PAW of aluminium alloys by variable polarity asymmetrical current began from 2000s. In Europe, a number of such companies as Merkle (Germany), EWM (Germany), Castolin (Switzerland), SBI (Austria), Migatronic Automation (Denmark) started batch production of equipment for PAW by variable polarity asymmetrical current with rectangular waveform. Some of these systems - Tetrix $350 \mathrm{AC} / \mathrm{DC}$ Plasma (EWM) and PMI-380 $\mathrm{AC} / \mathrm{DC}(\mathrm{SBI})$, can be used both for automatic and for manual PAW of aluminium alloys.

At the start of 1990s, PWI performed investigations of PAW of aluminium alloys by variable polarity asymmetrical current with rectangular

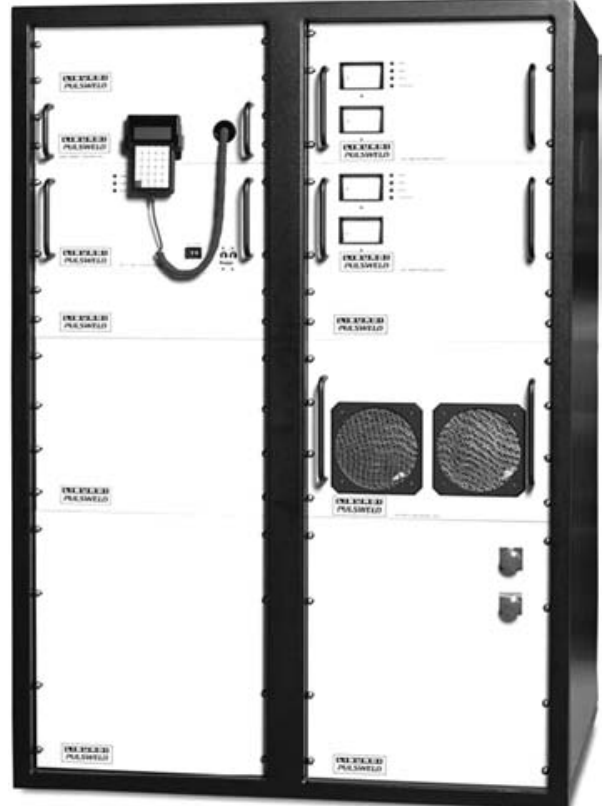

Figure 5. Appearance of LTP400-VP power source (Liburdi) for welding by VPPA process [18]

waveform using thyristor power sources with inductive energy storages. Investigation results showed that just temporary asymmetry is sufficient for sound weld formation, i.e. prevalence of the time of straight polarity current flowing and equality of straight and reverse polarity current amplitudes [24, 25].

In 2001, Fronius (Austria), based on PWI technical assignment developed a set of equipment for PAW of aluminium alloys by variable polarity asymmetrical current with rectangular waverform. The complex includes MW450 power source, FPM plasma module, filler wire feed

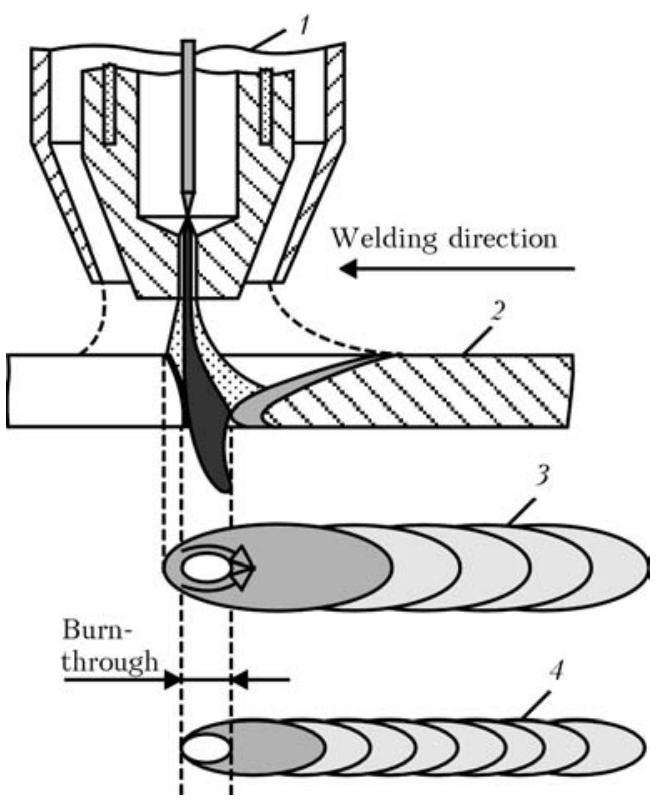

Figure 6. Block diagram of PAW in «keyhole» mode (ISF Aachen scheme) [22]: 1 - plasma torch; 2 - weld; 3 weld surface; 4 - weld root 


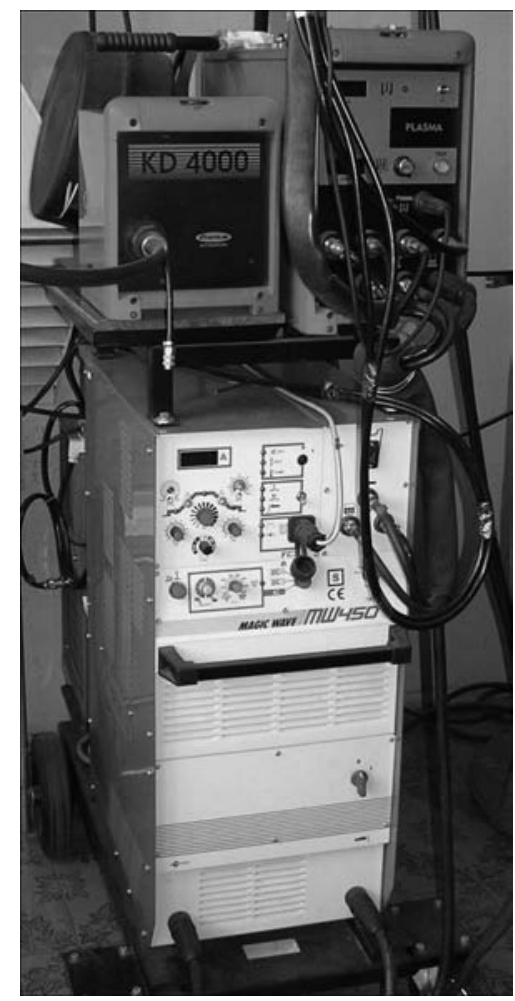

Figure 7. Fronius equipment for PAW of aluminium alloys by variable polarity asymmetrical current

mechanism KD 4000, plasmatron displacement system, welding process control system FPA 2003-Plasma, and independent water cooling unit (Figure 7). This equipment complex was used in PWI to develop a technology of PAW of aluminium-lithium alloys by variable polarity asymmetrical current [26, 27].

Unlike equipment for PAW of aluminium alloys of other companies, PAW system from Fronius is made by power source-plasma module scheme. Such a design allows selection of a power source of required power to solve the defined tasks. If not more than 150 A welding current is applied during operation, it is possible to use power sources of up to 220 A nominal power in the PAW system. All Fronius batch-produced power sources for nonconsumable-electrode argon-arc welding by variable polarity asymmetrical current (power sources of MW series) can be used as power sources for PAW.

Application of FPA 2003-Plasma system for welding process control allows significant expansion of the capabilities of PAW of aluminium

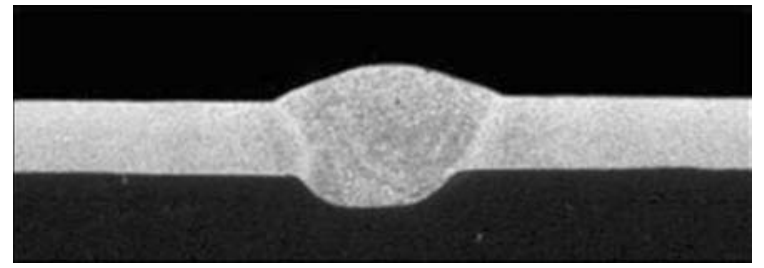

Figure 8. Macrosection of welded joint of D16 alloy $2 \mathrm{~mm}$ thick produced by PAW in downhand position

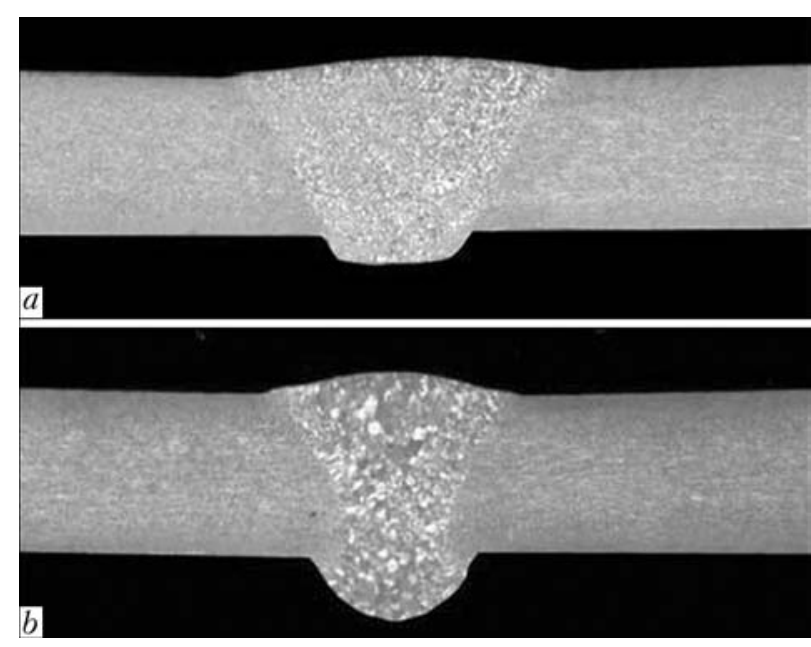

Figure 9. Macrosection of welded joint of $6 \mathrm{~mm}$ alloy 1420 ( $\mathrm{Al}-\mathrm{Li}-\mathrm{Mg})$ produced by downhand $\mathrm{PAW}$ on a backing with forming groove $(a)$ and in keyhole mode of plasma jet through-thickness penetration $(b)$

alloys by variable polarity asymmetrical current. So, the possibility of pulsed feed of plasma gas allows effectively preventing porosity in aluminium alloy welding, and welding current modulation and filler wire feeding at variable rate provides sound formation of welds in orbital welding of position butt joints. Investigations conducted at PWI confirmed that more precise regulation of parameters of PAW by variable polarity asymmetrical current, using FPA 2003Plasma welding process control system, allows application of this welding process to produce permanent joints of thin $(1-2 \mathrm{~mm})$ aluminium semifinished products (Figure 8), as well as to perform welding in the mode of through-thickness penetration of the plasma jet (Figure 9) [27].

Availability of machine and manual plasmatrons in the equipment range, as well as switching of plasma module operation allows equally efficient application of Fronius equipment for both automatic and manual plasma welding.

At present FPM plasma module has already been removed from production, and the new PlasmaModule-10 with digital control, unfortunately, does not provide PAW by variable polarity asymmetrical current.

Over the recent years several approaches have emerged to development of equipment for PAW of aluminium alloys by variable polarity asymmetrical current, namely development of specialized PAW systems and plasma modules (consoles) for connection to batch-produced power sources for tungsten electrode welding. In our opinion, application of additional plasma modules for creation of PAW system based on power sources for nonconsumable electrode welding will allow reduction of costs for setting up a welding station for constricted arc welding, improvement of versatility of 
equipment complex application, variation of the value of required power of welding sources, more complete realization of the technological capabilities of modern power sources for nonconsumable electrode welding.

Laser-plasma welding of aluminium alloys. Laser beam, being electrically neutral, can combine readily with consumable and nonconsumable electrodes at running in a common pool. Laser beam combines equally well in hybrid welding processes with nonconsumable-electrode constricted arc, running both at DCRP and variable polarity asymmetrical current. Hybrid laser-plasma welding of aluminium alloys allows narrowing the weld, increasing the penetration depth and welding speed, compared to regular PAW [28, 29].

Plasma-arc welding with powder application as filler. Aluminium alloy wire was traditionally used as filler material in PAW of aluminium alloys, both by direct and variable polarity current. Scientists of Chemnitz and Ilmenau Universities (Germany), suggested application of aluminium powder as filler material in PAW of aluminium alloys [30]. Aluminium powder application in PAW has several advantages, namely, interference from filler wire guides at movement of robotic «arms» is eliminated, it is possible to select filler material composition in a broad range, and quickly change the welding direction without turning the plasmatron with wire feed system fastened on it. The main disadvantage of application of aluminium powder as filler material is the large area, covered by oxide film, compared to filler wire. Extensive powder surface coated by oxide film, limited application of this welding process for joining less than $2 \mathrm{~mm}$ thick parts. The oxide film does not effectively break up in the arc at small values of welding current. At this moment the possibility of increasing arc power through application of helium-containing mixtures is being studied [31].

Two-sided plasma-arc welding and nonconsumable electrode welding. US scientists proposed joint application of plasmatron and nonconsumable electrode torch for aluminium alloy welding (Figure 10). In such a scheme the nonconsumable electrode torch is connected to the item instead of the cable mass [32]. Constricted nonconsumable electrode arc and freely expanding nonconsumable electrode arc, powered by one source, are simultaneously applied to the item from different sides. Such simultaneous arcing increases the voltage of both the arcs and penetration depth, and also improves the stability of through-thickness channel in welding in the mode of through-thickness penetration of the plasma arc [33].

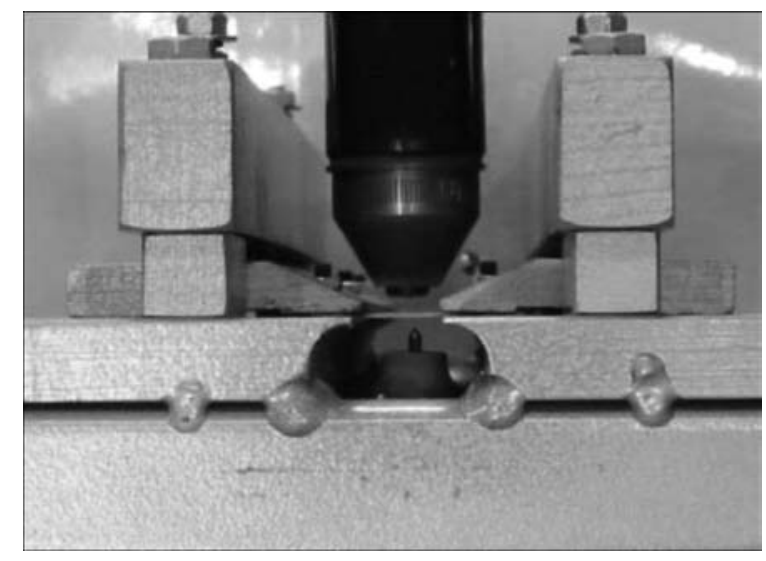

Figure 10. Two-sided PAW and nonconsumable electrode welding [32]

Combined application of plasma-arc welding and consumable electrode welding. Modern development of fabrication of aluminium structures, in particular, for extended constructions of ground and sea transportation, requires increasing the welding speed. One of the methods to solve such a task can be combined application of several welding processes, for instance, PAW and consumable electrode welding. So, in 20022005, PWI developed a technology of combined application of PAW by variable polarity asymmetrical current without filler material and consumable-electrode argon-arc welding (Figure 11). The distance between the two heat sources was $65 \mathrm{~mm}$, and common weld pool was absent. Nonconsumable electrode constricted plasma arc performed item heating and partial removal of hydrogen from the metal being melted. Weld convexity was formed due to electrode wire melting. Combined application of PAW by variable polarity asymmetrical current and consumable-electrode argon-arc welding at

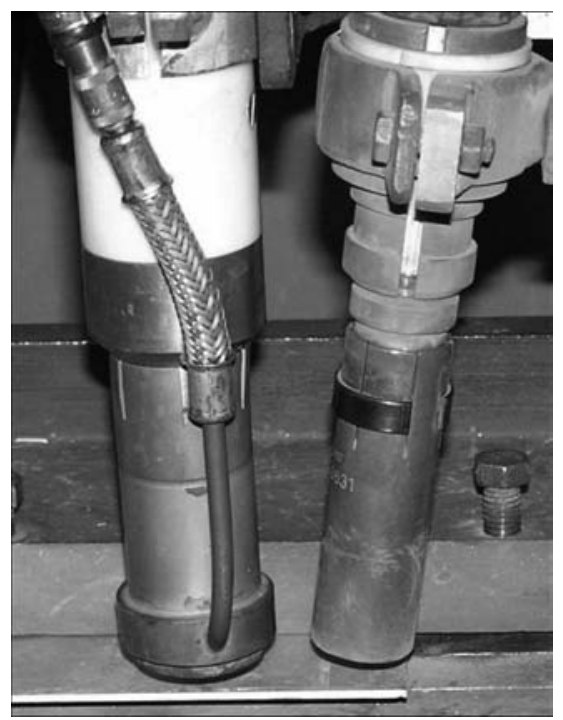

Figure 11. Position of plasmatron and consumable electrode torch at combined application of PAW and consumable electrode arc welding 


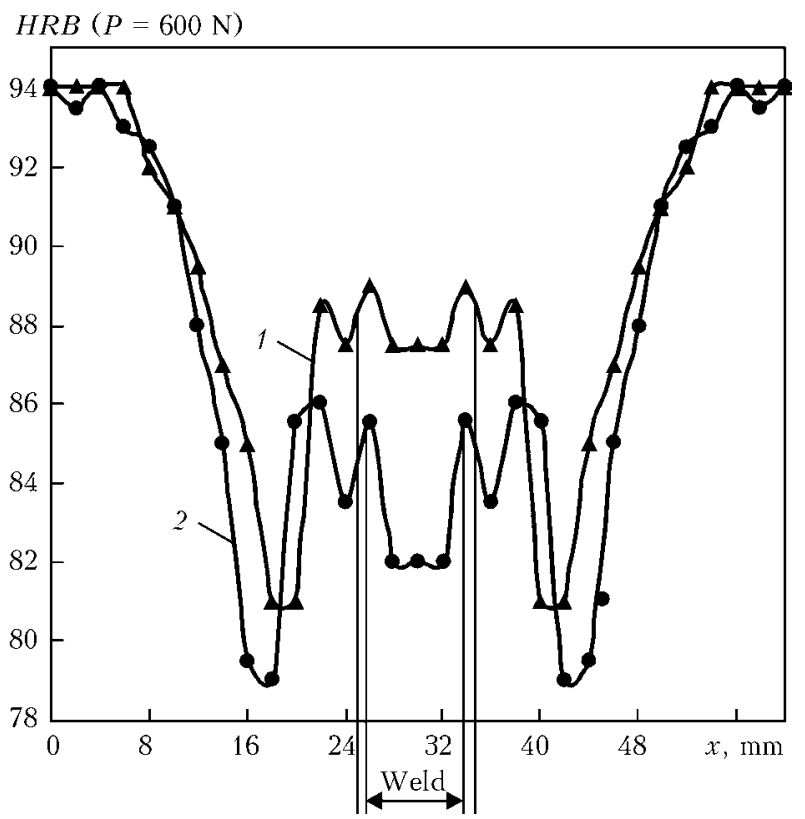

Figure 12. Hardness of deposits on $12 \mathrm{~mm}$ AMg6N alloy produced at combined application of PAW and consumable electrode welding (1) and at regular consumable electrode welding with filler wire of SvAMg6 grade (2)

achievement of the same penetration depth as that in regular consumable-electrode argon-arc welding, allows reducing the width of the weld

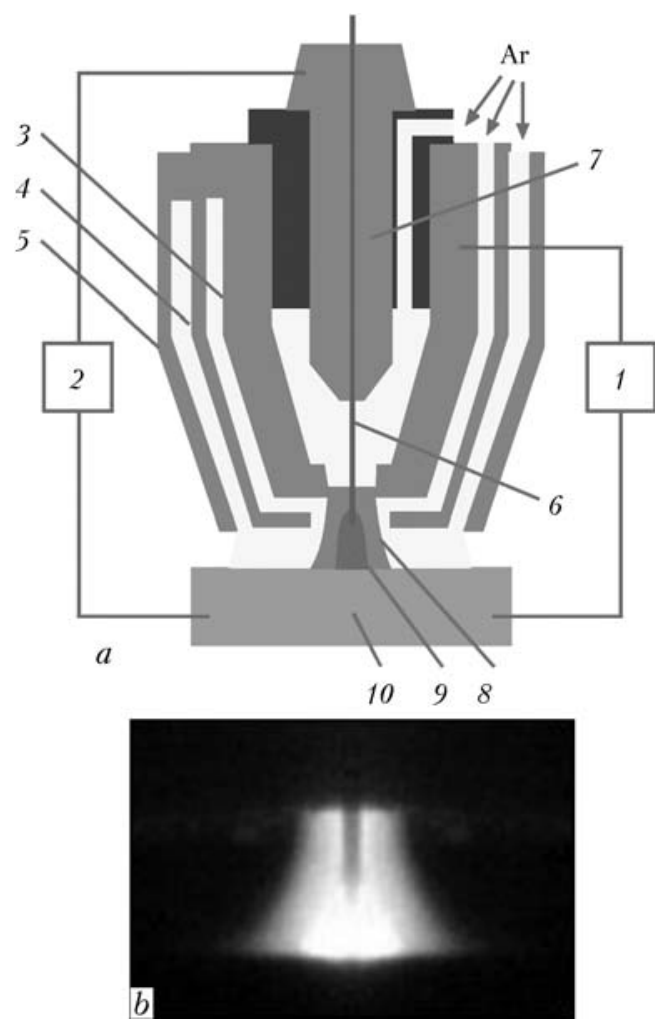

Figure 13. Schematic of the process $(a)$ and appearance of consumable electrode welding arc: 1 - constricted plasma arc power source; 2 - MIG-arc power source; $3-$ nonconsumable electrode; 4 - stabilizing nozzle; 5 - shielding nozzle; 6 - consumable electrode; 7 - current conduit; 8 - constricted plasma arc; 9 - MIG arc; 10 - item and base metal softening zone in welding, as well as the degree of this softening (Figure 12).

Hybrid consumable-electrode plasma-arc welding. One of the promising directions of development of the processes of aluminium alloy PAW is application of simultaneous arcing from several heat sources into a common pool, such as nonconsumable electrode constricted arc and consumable electrode arc, to form the weld pool (Figure 13). It was called Plasma-MIG abroad. This process was mentioned in 1970s, and the first patent for this welding process is owned by Philips Corporation [34]. Consumable electrode arc runs inside a nonconsumable electrode constricted arc. At present there exist two main schematics of this process realization: with annular anode (Figure 14) and with lateral position of the anode (Figure 15). Such a hybrid application of both the arcs allows reducing electrode metal spatter, increasing penetration depth and welding speed, and applying the process for welding thick items with groove preparation.

Investigations of hybrid consumable-electrode PAW are pursued in many universities in the world, in particular, at Chemnitz Technical University (Germany). A device was developed there, providing switching on and simultaneous operation of power sources for nonconsumable-electrode PAW at DCRP and power sources for consumable electrode welding at DCRP [35]. Investigations in this direction are also conducted at SLV Muenchen (Germany). Similar research is performed at Perm State University (Russia) [36, 37]. In Ukraine consumable-electrode PAW was studied at Priazovsky Technical University [38]. Features of the process of consumable-electrode PAW were also studied in China, Japan and Brazil [39, 40].

TBI (Germany) set up manufacture by individual orders of PLM 500 and PLM 600 torches with annular anode for consumable-electrode PAW, which can stand up to 250 and $300 \mathrm{~A}$ current load of DCRP for the torch plasma part and consumable electrode assembly, respectively (see Figure 14).

Plasma Laser Technologies Ltd. (Israel) proposed a process of hybrid consumable-electrode PAW, called Super-MIG, which involves simultaneous running of nonconsumable electrode constricted arc and consumable electrode arc into a common pool. Consumable electrode arc runs to the side of nonconsumable electrode arc (see Figure 15) [41].

Despite the high interest to hybrid consumable-electrode PAW with axial feed of electrode wire, batch-production of equipment for realiza- 


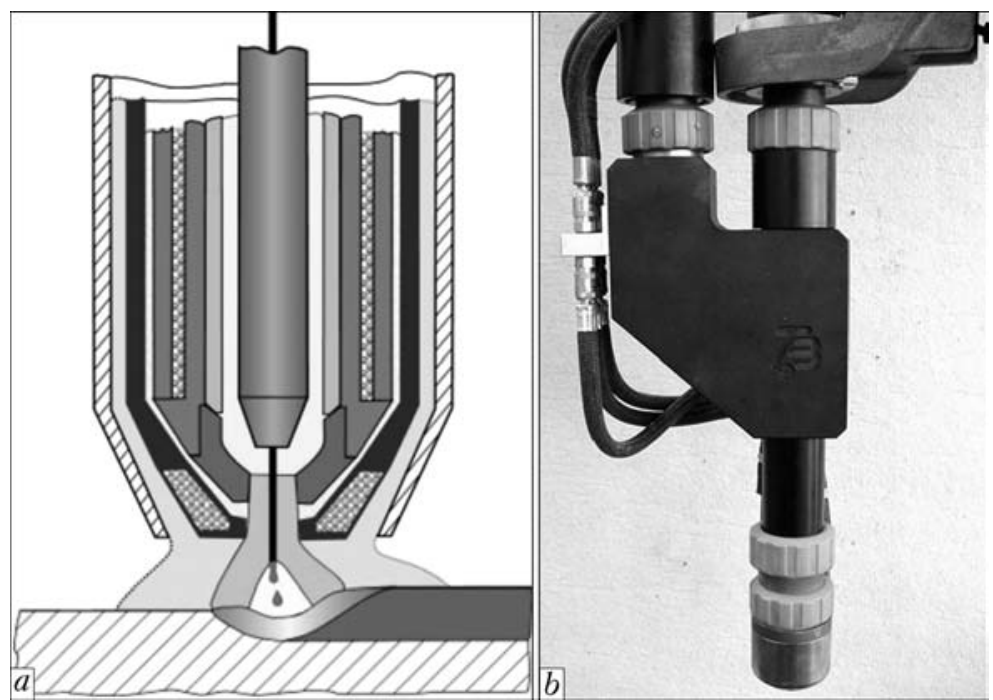

Figure 14. Schematic of the process of hybrid consumable-electrode PAW with annular hollow anode and axial feed of electrode wire $(a)$ and PLM 500 welding head of TBI for this method of welding $(b)$

tion of such a process has not been organized. Such equipment has a limited range of functions that significantly narrows the technological capabilities and application of this process.

In 2014-2015, PWI within a cooperation project with Chinese-Ukrainian E.O. Paton Welding Institute developed a versatile complex of equipment PLAZER PW-HYBRID TC for plasma-arc, combined and hybrid welding. Equipment manufacturer is Science-Production Center «Plazer» (Figure 16). This equipment complex allows realizing a broad range of plasma and arc processes: performing PAW with filler wire at DCSP and DCRP and variable polarity asymmetrical current, hybrid consumable-electrode PAW with annular anode of the plasmatron and with axial feed of electrode wire, combined welding by constricted arc and consumable electrode in «soft plasma» mode (soft plasma arc welding), and automatic consumable and nonconsumable electrode welding.
For realization of such a range of technological capabilities, this equipment is made to have modular design and includes the following main units:

- welding process control system, providing control of power sources, filler wire feed mechanisms, independent cooling modules, versatile multi-position manipulator for performance of various welding processes;

- inverter power source for welding plasmatron;

- inverter power source for consumable electrode;

- module for coordinating the operation of plasma welding and consumable electrode welding power sources in «Plasma + MIG» mode (hybrid and combined consumable-electrode PAW modes);

- plasmatron module for machine hybrid PAW «Plasma-MIG» with axial wire feed with cable hosepack;

- monoblock for combined «Plasma + MIG» welding with cable hosepack;

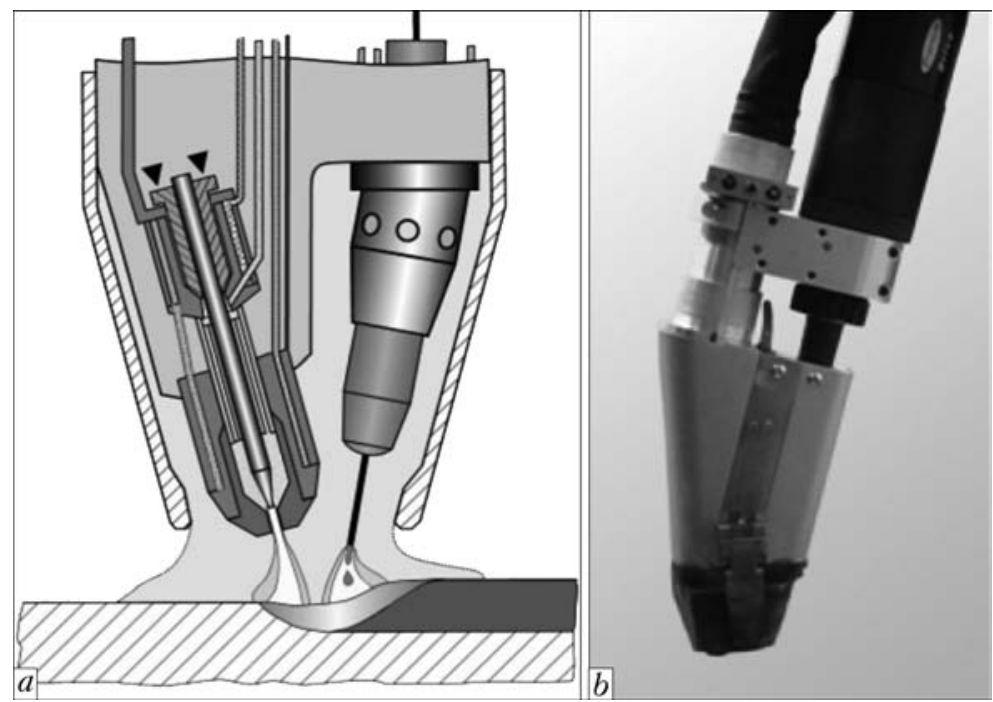

Figure 15. Schematic $(a)$ and welding torch for Super-MIG process (b) [41] 


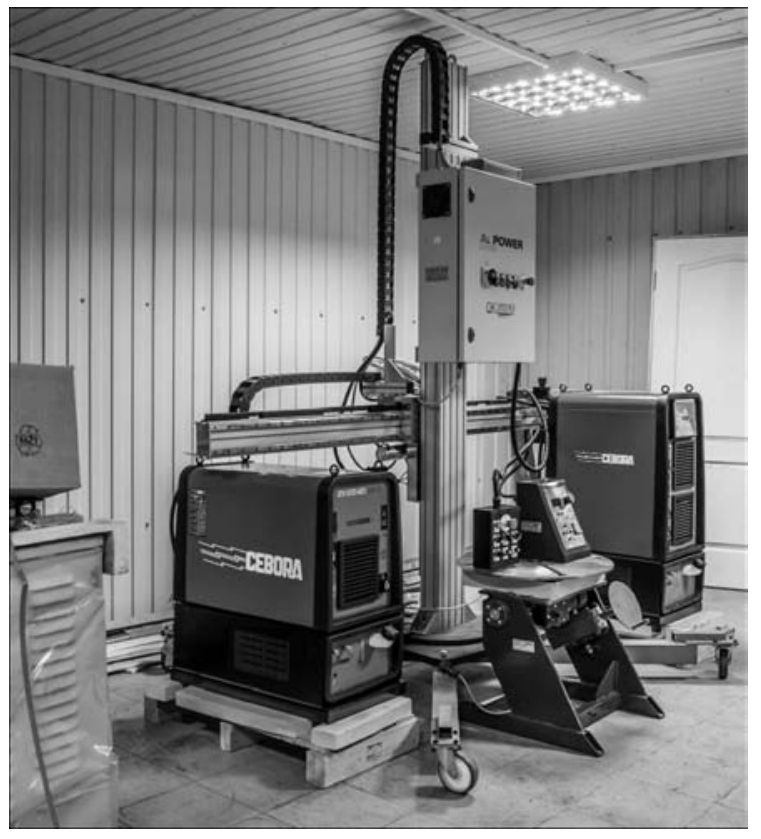

Figure 16. Appearance of versatile equipment complex PLAZER PW-HYBRID TC for plasma-arc, combined and hybrid welding in different positions

- filler wire feed mechanism for hybrid PAW «Plasma-MIG»;

- electrode wire feed mechanism for hybrid consumable-electrode PAW «Plasma + MIG»;

- independent cooling module for plasmatron and consumable electrode torch;

- multiposition welding manipulator for hybrid plasma welding in the downhand position, on vertical plane (including performance of vertical and horizontal welds on vertical plane), as well as for welding cylindrical parts.

In addition, the functions of this equipment provide the possibility of operation in a complex with welding robot instead of welding manipulator. For this purpose an interface is envisaged in the machine control system and in power
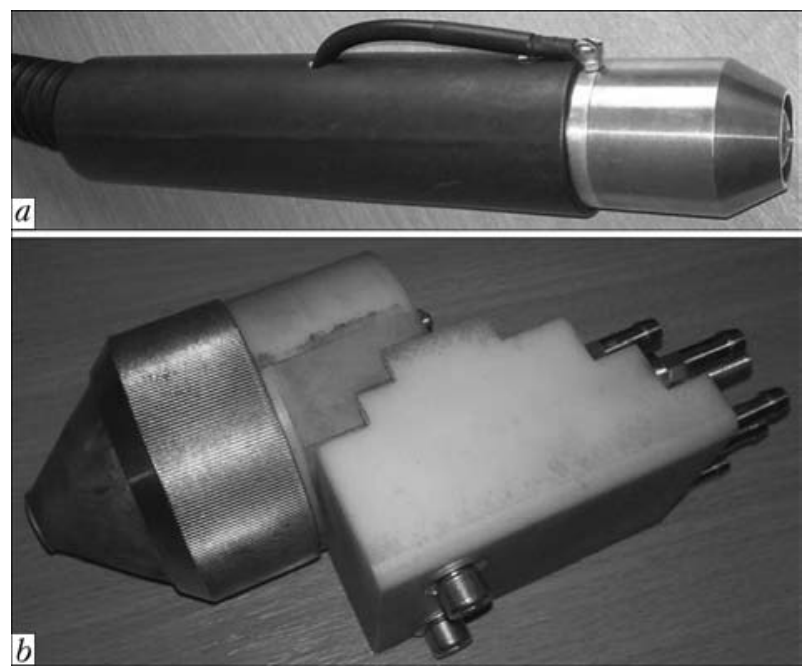

Figure 17. Plasmatrons developed by PWI for nonconsumable-electrode $(a)$ and hybrid consumable-electrode $(b)$ PAW sources for connection to a robot with communication protocols applied for the main types of advanced welding robots.

This equipment complex PLAZER PW-HYBRID TC (see Figure 16) allows making welds in the downhand position, vertical and horizontal welds on vertical and inclined planes. Availability of rotating welding positioner in the system design allows performance of circumferential welds by the above techniques. The complex is fitted with plasmatrons for nonconsumable and consumable electrode welding, developed by PWI (Figure 17).

In conclusion the following can be noted. PAW of aluminium alloys was developing as a continuation of nonconsumable-electrode argonarc welding with sinusoidal AC. The first apparatuses were based on power sources for nonconsumable electrode welding with alternating current. However, instability of running of sinusoidal AC arc, when passing through zero line, and considerable heating of plasmatron electrode assembly limited the possibility of wide application of PAW at sinusoidal AC of commercial frequency, both in FSU territory and abroad.

The next stage of development of PAW of aluminium alloys is application of DCRP for powering the constricted arc. This process has several advantages: equipment design simplicity, good cleaning of the surface of aluminium alloys and weld pool from oxide film inclusions. Large width of welds, higher susceptibility to hydrogen porosity formation, considerable overheating of plasmatron electrode assembly, leading to increase of plasmatron overall dimensions, should be regarded as disadvantages of this process, as well as greater wandering of DCRP constricted arc at small current amplitudes. At this moment this welding process is used occasionally, both for production and for research purposes.

Development of the next generation of power sources with rectangular current waveform for PAW allowed regulation in a broad range of straight and reverse polarity current amplitude, duration of straight and reverse polarity current flowing, as well as frequency of variable polarity current. Welding current form close to a rectangular one, simplified the processes of nonconsumable electrode arc excitation during reverse polarity half-wave at its transition through zero. Appearance of power sources with the possibility of creation of amplitude and time asymmetry of welding current provided a new impetus for development of PAW of aluminium alloys. In particular, VPPA welding process was the main one in manufacture in 1980-1990s of cryogenic fuel 
tanks from high-strength aluminium-lithium alloys for Space Shuttle system.

Simplification of the design of equipment for PAW by variable polarity asymmetrical current, as well as its cost reduction, is a favorable factor for introduction of this method not only into aerospace industry, but also into other mechanical engineering industries. Transition from specialized systems for PAW to modular design of the complex of equipment for PAW based on batch-produced sources for nonconsumable electrode welding also has a positive effect. Modular design in development of the equipment complex allows more precise adjustment for production engineering tasks.

Further promising direction of development of PAW of aluminium alloys is combined and hybrid application of two and more heat sources at welded joint formation. This will allow increasing the welding speed, reducing electrode metal spatter, and lowering the level of welded structure distortion. One of the promising fields is hybrid consumable-electrode PAW with plasmatron hollow annular anode and axial feed of electrode wire.

1. Gage, R.M. Arc torch and process. Pat. 2806124 US. Publ. 10.09.1957.

2. Lathi, K., Jenstroem, P. (1999) Plasma welding aluminium. Svetsaren, 3, 26-28.

3. Dzelnitzki, D. (2000) Aluplasmaschweissen: Gleichoder Wechselstrom? Technica (Suisse), 49(10), 44-53.

4. Dudko, D.A., Lakiza, S.P., Vinogradsky, F.M. et al. (1966) Alternating current constricted arc welding. Avtomatich. Svarka, 7, 47-49.

5. Dudko, D.A., Kornienko, A.N. (1967) Thermal effectiveness of alternating current plasma arc welding process. Ibid., 11, 27-30.

6. Rubinchik, Yu.L. (1974) Mechanized welding of hull structures from aluminium alloys. Leningrad: Sudostroenie.

7. Cooper, G., Palermo, J., Browning, J.A. (1965) Recent developments in plasma welding. Welding $J$. 44(4), 268-276.

8. Bykhovsky, D.G., Belyaev, V.M. (1971) Specifics of weld formation in plasma (constricted) arc welding of reverse polarity. Svarochn. Proizvodstvo, 9, 25-26.

9. Bykhovsky, D.G., Belyaev, V.M. (1971) Power characteristics of plasma arc at reverse polarity. Avtomatich. Svarka, 5, 27-30.

10. Nekrasov, S.A., Salkin, G.P., Bychkov, A.S. et al (1976) Application of plasma arc welding in production of cryogenic equipment from aluminium alloys. Svarochn. Proizvodstvo, 4, 16-17.

11. Gorbach, V.D., Bochkarev, V.P., Nazaruk, V.K. (2009) Technology of plasma welding of aluminium alloys. Mir Svarki, 3, 22-25.

12. Kiselev, G.S. (2010) Development of plasma welding technology of $A M g 5$ aluminium alloy with pulsed feed of plasma-forming gases: Syn. of Thesis for Cand. of Techn. Sci. Degree. Tula.

13. Tatarinov, E.A., Kiselev, G.S. (2009) To calculation of volt-ampere characteristic of plasma welding with pulsed feed of argon or helium. Svarka $i$ Diagnostika, 5, 11-14.

14. Bychkovsky, S.L., Novikov, O.M., Radko, E.P. et al. Method of plasma arc welding. Pat. 2351445 Russia. Appl. 2007121870/02, 14.06.2007.

15. Ruge, J., Lutze, P., Norenberg, K. (1989) Eignung von Aluminiumdruckguss zum Plasma- und Elektronenstrahlschweissen - Entgasungmechanismen und Nahtgute. Schweissen und Schneiden, 43(7), 327-332.
16. Schweinkhart, G. Plasma welding torch. Pat. 6215089B1 US. Pat. 10.04.2001.

17. Paton, B.E., Dudko, D.A., Gvozdetsky, V.S. et al. Method of plasma welding. USSR Author's cert. 221477. Int. Cl. B 23K9/16. Appl. 1164345/25-27, 17.06.67

18. Cert. 73735584 of VPPA trade mark registration. http: / www.tmfile.com / mark / ?q=737355845. Latest appeal 16.07.2015.

19. Micheli, J., Pilcher, C. (2000) Advanced variable polarity plasma arc welding. The Fabricator, November.

20. Nunes, A.C., Bayless, O.E., Jones, C.S. (1983) The variable polarity plasma arc welding process: Its application to the Space Shuttle External Tank: 1st report, June. Marshall Space Flight Center.

21. Clower, F.R. (1980) Welding of the external tank of the Space Shuttle. Welding J., 54(8), 17-26.

22. Tomsis, M., Barhorst, S. (1984) Keyhole plasma arc welding of aluminium with variable polarity power. Ibid., 63(3), 25-32.

23. (1998) Lockheed Martin Michoud Space Systems. Weld. Des. and Fabr., 71(11), 32.

24. Brik, E.Yu. (1989) Alternating current plasma arc welding of aluminium alloys. In: Abstr. of 1 st Int. Conf. of Junior Sci. in Welding and Related Technologies (Kiev, 16-20 May 1989), 91-92.

25. Zaparovany, A.G., Ignatchenko, G.N., Yarinich, L.M. et al. (1989) Power supply of pilot arc for variable polarity current plasma welding of aluminium. Avtomatich. Svarka, 9, 73-74.

26. Labur, T.M., Grinyuk, A.A., Poklyatsky, A.G. (2006) Mechanical properties of plasma welded joints on aluminium-lithium alloys. The Paton Welding J., 6, 32-34

27. Labur, T.M., Grinyuk, A.A., Taranova, T.G. et al. (2007) Features of micromechanism of fracture in joints of aluminium-lithium alloys produced by plasma welding. Ibid., 9, 11-16.

28. Krivtsun, I.V., Shelyagin, V.D., Khaskin, V.Yu. et al. (2007) Hybrid laser-plasma welding of aluminium alloys. Ibid., 5, 36-40.

29. Ternovoj, E.G., Shulym, V.F., Khaskin, V.Yu. et al. (2007) Properties and structure of hybrid laser-plasma welded joints in aluminium alloys. Ibid., 11, 10-15.

30. Wesling, V., Schraem, A., Bock, A. et al. (2004) Plasmapulververbindungsschweissen von Aluminumblechen. Praktiker, 10, 288-294.

31. (2005) Untersuchung der metallurgischen Grundlagen zum Plasma-Pulver-Verbindungsschweissen duenner Aluminiumbleche. Schlussbericht fuer den Zeitraum: 1.6.2003 bis 31.5.2005. AiF Vorhaben $13.770 \mathrm{~B} / 4$. Technische Universitaet Ilmenau.

32. Zhang, Y.M., Zhang, S.B. (1998) Double side arc welding increases weld joint penetration. Welding $J ., 6,57-61$.

33. Moulton, J.A., Weckman, D.C. (2010) Double side arc welding of 5182-O aluminum sheet for tailored welded blank applications. Ibid., 1, 11-23.

34. Method of plasma-MIG welding. Pat. 3809824 U.S. Pat. 24.06.75. U.S. Philips Corporation.

35. Matthes, K.-J., Kusch, M. (2000) Plasma-MIGSchweissen. Praktiker, 5, 182-188.

36. Shchitsyn, Yu.D., Tytkin, Yu.M. (1986) Consumable electrode plasma welding of aluminium alloys. Svarochn. Proizvodstvo, 5, 1-2.

37. Shchitsyn, Yu.D., Shchitsyn, V.Yu., Herold, H. et al. (2003) Plasma welding of aluminium alloys. Ibid., 5, 36-42.

38. Makarenko, N.A., Nevidomsky, V.A. (2003) Thermal cycles in plasma-MIG surfacing. The Paton Welding J., 1, 43-45.

39. Yan, B., Hong-Ming, G., Ling, Q. (2010) Droplet transition for plasma-MIG welding on aluminium alloys. Transact. of Nonferrous Met. Soc. China, 20, $2234-2239$

40. Tiago Vieira da Cuhna, Jair Carlos Dutra (2007) Processo plasma-MIG contribuicao do arco plasma na capacidade de fusao do arame. Soldagem Insp. Sao Paulo, 12(2), 89-96

41. (2007) Hybrid welding: An alternative to SAW. Welding J., 10, 42-45. 